\title{
Involvement of TLR7 MyD88-dependent signaling pathway in the pathogenesis of adult-onset Still's disease
}

Der-Yuan Chen ${ }^{1,2,3,4,5^{*}+}$, Chi-Chen Lin ${ }^{5+}{ }^{4}$ Yi-Ming Chen ${ }^{1,2}$, Joung-Liang Lan ${ }^{6}$, Wei-Ting Hung ${ }^{1,2}$, Hsin-Hua Chen ${ }^{1,2}$, Kuo-Lung Lai ${ }^{1,2}$ and Chia-Wei Hsieh ${ }^{2}$

\begin{abstract}
Introduction: The objective of this study was to investigate the potential role of the Toll-like receptor 7 (TLR7) signaling pathway in the pathogenesis of adult-onset Still's disease (AOSD).

Methods: Frequencies of TLR7-expressing precursor of myeloid dendritic cells (pre-mDCs) and mDCs in 28 AOSD patients, 28 patients with systemic lupus erythematosus (SLE) and 12 healthy controls (HC) were determined by flow cytometry analysis. Transcript and protein levels of TLR7 signaling molecules in peripheral blood mononuclear cells (PBMCs) were evaluated by quantitative PCR and western blotting respectively. Serum cytokines levels were measured by ELISA.
\end{abstract}

Results: Significantly higher median frequencies of TLR7-expressing pre-mDCs and mDCs were observed in AOSD patients (65.5\% and $14.9 \%$, respectively) and in SLE patients (60.3\% and $14.4 \%$, respectively) than in HC (42.8\% and $8.8 \%$, respectively; both $P<0.001)$. Transcript and protein levels of TLR7-signaling molecules, including MyD88, TRAF6, IRAK4 and IFN- $\alpha$, were upregulated in AOSD patients and SLE patients compared with those in HC. Disease activity scores were positively correlated with the frequencies of TLR7-expressing $\mathrm{mDCs}$ and expression levels of TLR7 signaling molecules in both AOSD and SLE patients. TLR7 ligand (imiquimod) stimulation of PBMCs resulted in significantly enhanced levels of interleukin (IL)-1 $1 \beta, I L-6, I L-18$ and IFN- $\alpha$ in AOSD and SLE patients. Frequencies of TLR7-expressing mDCs and expression levels of TLR7 signaling molecules significantly decreased after effective therapy.

Conclusions: Elevated levels of TLR7 signaling molecules and their positive correlation with disease activity in AOSD patients suggest involvement of the TLR7 signaling pathway in the pathogenesis of this disease. The overexpression of TLR7 MyD88-dependent signaling molecules may be a common pathogenic mechanism for both AOSD and SLE.

\section{Introduction}

Toll-like receptors (TLRs) represent an important link between innate and adaptive immune responses [1,2]. Recent studies have shown that recognition of selfnucleic acid by TLRs plays a critical role in the pathogenesis of autoimmunity and inflammation $[3,4]$. TLR expression patterns vary among antigen-presenting cells. For example, human myeloid dendritic cells (mDCs) lack

\footnotetext{
* Correspondence: dychen@vghtc.gov.tw

+ Contributed equally

'Faculty of Medicine, National Yang-Ming University, No. 155, Sec. 2, Li-Nong Street, Taipei 112, Taiwan

Full list of author information is available at the end of the article
}

TLR9 but express TLR7, which recognizes nucleic acids $[5,6]$. Endosomally located TLRs of DCs, such as TLR7, are involved in the tissue inflammation of autoimmune diseases, such as systemic lupus erythematosus (SLE) $[3,4,7,8]$. Treatment of lupus-prone mice with a dual inhibitor of TLR7 and TLR9 leads to the reduction of autoantibody production and disease activity [9]. Therefore, TLR7-mediated DCs are implicated in the pathogenesis of systemic inflammatory diseases.

TLR7 ligation may induce signal transduction via the myeloid differentiation primary-response protein 88 (MyD88), a common adaptor molecule $[2,10,11]$. The 
activation of MyD88 signaling leads to the production of type I IFN and proinflammatory cytokines through a group of cytosolic adaptor molecules, including IL-1 receptor-associated kinase (IRAK)-1/4, tumor necrosis factor receptor- associated factor (TRAF)-6, and IFN regulatory factor (IRF) $-5 / 7[2,10]$. In addition, Thibault et al. indicated a critical link between the type 1 IFN pathway and the regulation of TLR7-specific immune responses in a murine SLE model [12].

Adult-onset Still's disease (AOSD) is an inflammatory disorder, characterized by fever, rash, arthritis, involvement of various organs, neutrophilic leukocytosis, and increased acute phase reactants [13,14]. Although aetiopathogenesis of AOSD remains unclear, the interplay of viral infections, genetic factors, and immune dysregulation, including cytokine-mediated inflammation and elevated apoptosis, may contribute to the development of this disease [15-19]. Nucleic acids derived from viruses or released from damaged host cells can act as ligands for TLR7 $[2,5,9,20]$ and may promote inflammatory diseases [9]. Previous studies showed that TLR7 ligation could promote the recruitment of neutrophils and amplification of Th17-driven inflammatory responses in inflammatory disease [21], and TLR7 ligation-generated inflammatory cytokines that combine to potentiate Th17 differentiation [22]. Our recent study also showed an important role of Th17 cells in AOSD pathogenesis [23]. Therefore, we hypothesize that TLR7 plays a potential role in AOSD pathogenesis. However, there are no data concerning the TLR7 signaling pathway in AOSD.

In this study, the expression levels of TLR7 were quantified in circulating precursors of $\mathrm{mDCs}$ (pre-mDCs) and in mDCs using flow cytometry analysis. The transcript and protein levels of TLR7 signaling molecules in peripheral blood mononuclear cells (PBMCs) were determined using quantitative PCR and western blotting respectively. We enrolled SLE patients, who have some shared clinical manifestations with AOSD, as the disease control because previous studies have documented TLR7 expression in SLE $[9,24,25]$. The association of TLR7 expression levels with disease activity parameters and downstream cytokines levels was also investigated. To explore the functional role of TLR7, PBMCs were stimulated with TLR7 ligand, after which, supernatant levels of downstream cytokines were evaluated. The changes in the expression levels of TLR7 signaling molecules during longitudinal follow-up of AOSD patients were also studied.

\section{Methods}

\section{Patients}

Twenty-eight patients with active untreated AOSD (twenty female and eight male patients, mean age \pm SD, $37.4 \pm 14.8$ years) fulfilling the Yamaguchi criteria [26] were enrolled. Patients with infections, malignancies or other rheumatic diseases were excluded. The disease activity for each AOSD patient was assessed using a modified Pouchot score described by Rau et al. [27]. After initial investigation for TLR7 signaling, all AOSD patients received corticosteroids and non-steroidal antiinflammatory drugs (NSAIDs). The disease-modifying anti-rheumatic drugs (DMARDs) used were methotrexate (twenty-three patients), hydroxychloroquine (twenty patients), sulfasalazine (ten patients), and azathioprine (six patients). Twenty-eight age-matched patients (twenty-five female and three male patients, mean age $38.2 \pm 8.7$ years) fulfilling the 1997 revised criteria of the American College of Rheumatology (ACR) for SLE [28] were included as disease controls for systemic inflammation. Disease activity in SLE was determined by calculating the SLE disease activity index (SLEDAI) [29]. Twelve age-matched healthy volunteers (eight female and four male patients, mean age $36.4 \pm 9.2$ years), who had no rheumatic disease, were used as normal controls. The Ethics Committee of Clinical Research, Taichung Veterans General Hospital, approved this study and the participant's written consent was obtained according to the Declaration of Helsinki.

\section{Quantitation of the expression levels of TLR7 in mDCs using flow cytometry analysis}

PBMCs were isolated from peripheral blood using FicollHypaque (Amersham Biosciences, Sweden) density gradient centrifugation. For detection of intracellular expression of TLR7 on pre-mDCs (phenotypically defined as CD14 ${ }^{+} \mathrm{CD} 11 \mathrm{c}^{+}$cells), and mDCs (phenotypically defined as $\mathrm{CD} 14^{+} \mathrm{CD} 11 \mathrm{c}^{+}$cells), we performed flow cytometry analysis for three-colored staining of PBMCs with a mixture of phycoerythrin-Cyanin 5 (PE-Cy5)-conjugated anti-CD14 (Beckman Coulter, Brea, CA, USA), fluorescein isothiocyanate (FITC)-conjugated anti-CD11c (eBioscience, San Diego, CA, USA), and PE-conjugated TLR7-specific mAb (R\&D Systems, Minneapolis, MN, USA) using a mild modification of the described technique [24,25]. After staining, the cells were washed and immediately analyzed using flow cytometry (Beckman Coulter). An isotype control IgG1-PE (eBiosciences) was used for TLR7 staining at room temperature in the dark. Data were obtained using an Epics XL (Beckman Coulter), and the results were analyzed using EXPO32 software (Beckman Coulter).

\section{Determination of the mRNA expression (transcript) levels} of TLR7signaling on PBMCs using quantitative PCR (qPCR) To explore TLR7 signaling in the pathophysiology of AOSD and SLE, we examined the transcript levels for signaling molecules on PBMCs using qPCR. Total cellular RNA was obtained from PBMCs by the guanidinium isothiocyanate method [30] and was quantified by spectrophotometry at $260 \mathrm{~nm}$. A $2.5-\mu \mathrm{g}$ RNA aliquot was reverse- 
transcribed with $200 \mathrm{U}$ of Moloney murine leukemia virus reverse transcriptase (Fermentas, Thermo Fisher Scientific Inc. Waltham, MA, USA) according to standard procedures. The qPCR was performed using $\mathrm{IQ}^{2}$ Fast qPCR System (Bio-genesis Technology Inc., Taipei, Taiwan) with a method modified from previous reports [25]. The following oligonucleotide primers for each molecule of TLR7 signaling were designed and synthesized. For TLR7, sense primer 5'-TTACCTGGATGGAAACCAGCTACT- 3'and antisense primer 5'-TCAAGGCTGAGAAGCTGTAAGCTA-3'; for MyD88, sense primer 5'-GAGCGTTTCGATGCCTTCAT-3' and antisense primer 5'-CGG ATCATCTCCTGCACAAA-3'; for TRAF6, sense primer 5'-GATGCAGAGGAA TCACTTGGC-3' and antisense primer 5'-GGTCTGTCTTACAAGGCGAC-3'; for IRAK4, sense primer 5'-GCTGCTGCAAGAGATGACAG-3' and antisense primer 5'-CACTGTCCTGCAACAGCCTA-3'; for IRF5, sense primer 5'-GGAGCATTT TCTCAATGAGCTCATC-3' and antisense primer 5'-CTGCTACAGGCACCAC CTGTACAGT-3'; for IFN- $\alpha$, sense primer 5'-TGCTTTACTGATGGTCCTGGT-3' and antisense primer 5'-TCATGTCTGTCCATCAGACAG-3', and for the housekeeping gene Glyceraldehyde-3-phosphate dehydrogenase (GAPDH), sense primer 5'-GACCTGACCTGCCGTCTAGAAA-3' and antisense primer 5'CCTGCTTCACCACCTTCTTGA-3'. PCR was performed in a total volume of $10.0 \mu \mathrm{L}$ containing $10 \mathrm{ng}$ of cDNA, 5 $\mu \mathrm{L} 2 \times$ IQ2 fast qPCR system master mix, $0.375 \mu \mathrm{L}$ each of oligonucleotide primer, and RNase-free water. Amplification cycles were $95^{\circ} \mathrm{C}$ for $10 \mathrm{~min}$, followed by 40 cycles of denaturation at $95^{\circ} \mathrm{C}$ for 10 s, then annealing and extension at 60 to $62^{\circ} \mathrm{C}$ for 30s. To standardize mRNA levels of each target gene, transcript levels of the housekeeping gene GAPDH were determined in parallel for each sample. The relative expression level of each target gene was calculated with the comparative threshold cycle $(\mathrm{Ct})$ method and evaluated by:

$$
2^{-\Delta \Delta \mathrm{Ct}}, \Delta \Delta \mathrm{Ct}=\text { Patient }\left(\mathrm{Ct}_{\text {target gene }-\mathrm{Ct}} \mathrm{CAPDH}_{\mathrm{APH}}\right)-\text { Mean of controls }\left(\mathrm{Ct}_{\text {target gene }}-\mathrm{Ct}_{\mathrm{CAPDH}}\right) .
$$

\section{Determination of protein expression levels of TLR7signaling} molecules in PBMCs using western blot analysis

Immunoblot analysis of protein expression of TLR7 signaling molecules in the lysates of PBMCs from AOSD patients, SLE patients, and healthy volunteers were performed as described in our recent study [31]. An equal amount of cell extracts from each set of experiments were fractionated on 6 to $8 \%$ SDS-PAGE in running buffer (25mM Tris, $192 \mathrm{mM}$ glycine, $0.1 \% \mathrm{SDS}$ ). The gel was run at $90 \mathrm{~V}$ for 30 minutes then at $130 \mathrm{~V}$ until the blue dye front reached the bottom. The gel was transferred to polyvinylidene difluoride membrane (PVDF) in transfer buffer (50 mM Tris, $384 \mathrm{mM}$ glycine, $20 \%$ methanol) at $21 \mathrm{~V}$ for
$1 \mathrm{hr}$ with the Trans-Blot SD Semi-Dry Electrophoretic Transfer Cell (BIO-RAD, Hercules, CA, USA). The membranes were blocked with $5 \%$ BSA in $150 \mathrm{mM} \mathrm{NaCl}$, $20 \mathrm{mM}$ Tris- $\mathrm{HCl}$ (pH 7.4), 0.1\% Tween-20 (TBST) at room temperature for $1 \mathrm{hr}$ then probed with antibodies for TLR7 signaling molecules (Santa Cruz Biotechnology, Santa Cruz, CA, USA), which was generated by immunizing rabbits with the appropriate peptide and antibodies for $\beta$-actin (Santa Cruz Biotechnology) at $4^{\circ}$ Covernight. The membranes were washed about three times with TBST, followed by incubation with peroxidase-conjugated secondary antibody (1:6000) at room temperature for $1 \mathrm{hr}$. The membranes of antibody reaction were washed three times with TBST and performed using the enhanced Immobilon Western Chemiluminescent HRP Substrate (WBKLS0500, Millipore, Billerica, MA, USA) then exposed with the new MegaCam 810 scientific grade CCD camera (UVP, LLC, Upland, CA, USA). The relative expression level of TLR7 signaling molecules was normalized to $\beta$-actin, and values were expressed relative to control.

\section{Determination of serum levels of proinflammatory cytokines}

Serum levels of IL-1 $\beta$, IL-6, IL-18, TNF- $\alpha$, and IFN- $\alpha$ were determined in AOSD patients, SLE patients and healthy controls using ELISA according to the manufacturer's instructions (eBiosciences).

\section{Ex vivo induction of cytokines on PBMCs treated with TLR7 ligand}

To explore the functional role of TLR7 activation in the pathophysiology of AOSD and SLE, we examined the changes in supernatant levels of downstream cytokines on PBMCs treated with TLR7 ligand with a method modified from previous reports [32]. PBMCs were obtained from ten AOSD patients, ten SLE patients, and six healthy controls, and were re-suspended in Roswell Park Memorial Institute (RPMI) 1640 medium (Sigma, USA) supplemented with 100 units $/ \mathrm{mL}$ penicillin, $100 \mu \mathrm{g} / \mathrm{mL}$ streptomycin, and $10 \%$ fetal blood serum in a final concentration of $1 \times$ $10^{6}$ cells/well. PBMC samples were incubated at $37^{\circ} \mathrm{C}$ in a $5 \% \mathrm{CO}_{2}$ humidified atmosphere for $24 \mathrm{hr}$ in the absence or presence of the TLR7 ligand, imiquimod $(5 \mu \mathrm{g} / \mathrm{mL}$, InvivoGen, San Diego, CA, USA). The cell-free supernatant was harvested, and the levels of TLR7-signaling downstream cytokines, including IL-1 $\beta$, IL- 6 , IL-18, TNF- $\alpha$, and IFN- $\alpha$ were determined by ELISA (eBiosciences). A sample with undetectable cytokines was arbitrarily defined as $0 \mathrm{pg} / \mathrm{mL}$.

\section{Statistical analysis}

Results are presented as the mean \pm SD or median (IQR). The nonparametric Kruskal-Wallis test was used for 
between-group comparison of the frequencies of TLR7expressing pre-mDCs and $\mathrm{mDCs}$, transcript and protein levels of TLR7 signaling molecules, and serum levels of proinflammatory cytokines. When this test showed significant differences, then the exact $P$-values were determined using the Mann-Whitney $U$-test. The correlation coefficient was obtained by the nonparametric Spearman's rank correlation test. The Wilcoxon signed rank test was employed to compare changes in supernatant cytokines levels from TLR7 ligand-treated PBMCs, and changes in transcript levels of TLR7 signaling molecules during follow-up in AOSD patients after effective therapy. Probability less than 0.05 was considered significant.

\section{Results}

Clinical characteristics of AOSD patients and SLE patients As illustrated in Table 1, all patients with active AOSD had spiking fevers $\left(\geq 39^{\circ} \mathrm{C}\right)$. Evanescent rash, arthritis, sore throat, and lymphadenopathy were noted in 25 (89.3\%), 20 (71.4\%), 18 (64.3\%), and 7 (25.0\%) patients respectively. All SLE patients had active disease (mean SLEDAI \pm SD, $7.8 \pm 2.3$, range 6.0 to 14.0 ) at the time of investigation and nine patients $(32.1 \%)$ had renal involvement. However, there were no significant differences between AOSD patients and SLE patients in age at onset, proportion of females, or frequencies of extrarenal manifestations.

Table 1 Demographic data and clinical characteristics of patients with adult-onset Still's disease (AOSD), patients with systemic lupus erythematosus (SLE) and healthy controls (HC)

\begin{tabular}{|c|c|c|c|}
\hline Characteristics & $\begin{array}{c}\text { AOSD } \\
(n=28)\end{array}$ & $\begin{array}{c}\text { SLE } \\
(n=28)\end{array}$ & $\begin{array}{c}\mathrm{HC} \\
(n=12)\end{array}$ \\
\hline Age at study entry, years & $37.4 \pm 14.8$ & $38.2 \pm 8.7$ & $36.4 \pm 9.2$ \\
\hline Proportion of females & $20(71.4 \%)$ & $25(89.3 \%)$ & $8(66.7 \%)$ \\
\hline Fever $\left(\geqq 39^{\circ} \mathrm{C}\right)$ & $28(100 \%)$ & $24(85.8 \%)$ & NA \\
\hline Rash & $25(89.3 \%)$ & $21(75.0 \%)$ & NA \\
\hline Arthritis & $20(71.4 \%)$ & $15(53.6 \%)$ & NA \\
\hline Lymphadenopathy & $7(25.0 \%)$ & $6(21.4 \%)$ & NA \\
\hline Nephritis & $0(0.0 \%)$ & $9(32.1 \%)^{*}$ & NA \\
\hline Ferritin levels, $\mu \mathrm{g} / \mathrm{L}$ & $931.0 \pm 106.5$ & NA & NA \\
\hline AOSD activity score & $5.93 \pm 1.46$ & NA & NA \\
\hline SLEDAI & N A & $7.8 \pm 2.3$ & NA \\
\hline C3 levels, mg/dL & NA & $84.6 \pm 24.7$ & NA \\
\hline C4 levels, mg/dL & NA & $19.5 \pm 8.9$ & NA \\
\hline Anti-ds DNA, U/mL & NA & $183.2 \pm 200.3$ & NA \\
\hline
\end{tabular}

Data are presented as mean \pm SD or number (percentage); NA, not applicable Nephritis is defined by persistent proteinuria ( $>0.5 \mathrm{~g} / 24$ hours), the presence of cellular casts, or pathological examination of renal biopsy specimens showing lupus nephritis. C3 and C4, complement 3 and 4; Anti-ds DNA, antidouble strand DNA antibody; SLEDAl, SLE disease activity index; ${ }^{*} P<0.001$, versus AOSD patients.
The circulating levels of TLR7-expressing mDCs in AOSD patients and SLE patients

Because the classical CD14+ monocytes constitute the vast majority of all monocytes in peripheral blood, we examined the percentages of TLR7-expressing cells in each subset of myeloid DCs, including pre-mDCs $\left(\mathrm{CD} 14^{+} \mathrm{CD} 11 \mathrm{c}^{+}\right.$ cells) and mDCs (CD14 ${ }^{-} \mathrm{CD} 11 \mathrm{c}^{+}$cells). As shown in Figure 1, significantly higher percentages of TLR7-expressing pre-mDCs and $\mathrm{mDCs}$ were observed in patients with active AOSD (median $65.5 \%$, IQR 60.2 to $73.7 \%$, and $14.9 \%$, IQR 12.5 to $18.8 \%$; for pre-mDCs and mDCs, respectively) and SLE (median 60.3\%, IQR 52.1 to $68.1 \%$ and $14.4 \%$, IQR 12.5 to $18.0 \%$, respectively) than in healthy controls (median 42.8\%, IQR 36.9 to $51.7 \%$ and $8.8 \%$, IQR 5.1 to $11.1 \%$, respectively) (all $P<0.001$ ). Significantly higher mean fluorescence intensity (MFI) of TLR7 staining on circulating pre-mDCs and mDCs was also observed in patients with active AOSD (median 7.23, IQR 5.00 to 8.69 and 9.30, IQR 6.85 to 11.35 , respectively) and in active SLE (median 6.69, IQR 5.69 to 9.84 and 8.80, IQR 7.08 to 10.35 , respectively) than in healthy controls (median 3.47 , IQR 2.88 to 4.78 and 4.65 , IQR 2.98 to 6.00 , respectively) (all $P<0.001$ ). However, there was no significant difference between AOSD patients and SLE patients in the expression level of TLR7 on circulating pre-mDCs or mDCs. There was no significant difference between the two patient groups and the healthy controls in the numbers of pre-mDCs or mDCs cells that were gated for MFI (data not shown).

The transcript and protein levels of TLR7 MyD88dependent signaling pathway

As shown in Figure 2, significantly higher transcript levels of TLR7, MyD88, IRAK4, TRAF6, and IFN- $\alpha$ were observed in active AOSD patients (median 145.64, IQR 7.07 to $814.81 ; 2.08$, IQR 1.53 to $8.55 ; 4.55$, IQR 1.55 to 14.49; 13.86 , IQR 4.80 to $45.04 ; 46.23$, IQR 15.51 to 154.05 , respectively) than those in healthy controls $(0.48$, IQR 0.23 to $8.62 ; 1.12$, IQR 0.79 to $1.40 ; 0.59$, IQR 0.51 to 2.62; 0.55 , IQR 0.40 to $3.80 ; 0.61$, IQR 0.10 to 11.30 , respectively (all $P<0.001$ ). Significantly higher transcript levels of TLR7, MyD88, and IFN- $\alpha$ were also observed in active SLE patients (median 43.47, IQR 9.30 to 103.07; 2.08, IQR 0.85 to $4.87 ; 24.91$, IQR 6.20 to 188.90 , respectively) than those in healthy controls $(P<0.001, P<0.05$, $P<0.001$, respectively). No significant differences were observed between AOSD or SLE patients and healthy controls in the transcript levels of IRF-5.

As illustrated in Figure $2 \mathrm{G}$ and $2 \mathrm{H}$, protein expression levels of TLR7, MyD88, IRAK4, TRAF6, and IFN$\alpha$ were upregulated in patients with active AOSD (relative expression levels, mean \pm SEM, $1.57 \pm 0.04,1.65 \pm$ $0.12,1.45 \pm 0.13,1.91 \pm 0.14,1.09 \pm 0.06$, respectively) and SLE $(1.29 \pm 0.04,1.49 \pm 0.10,1.30 \pm 0.18,1.47 \pm$ 

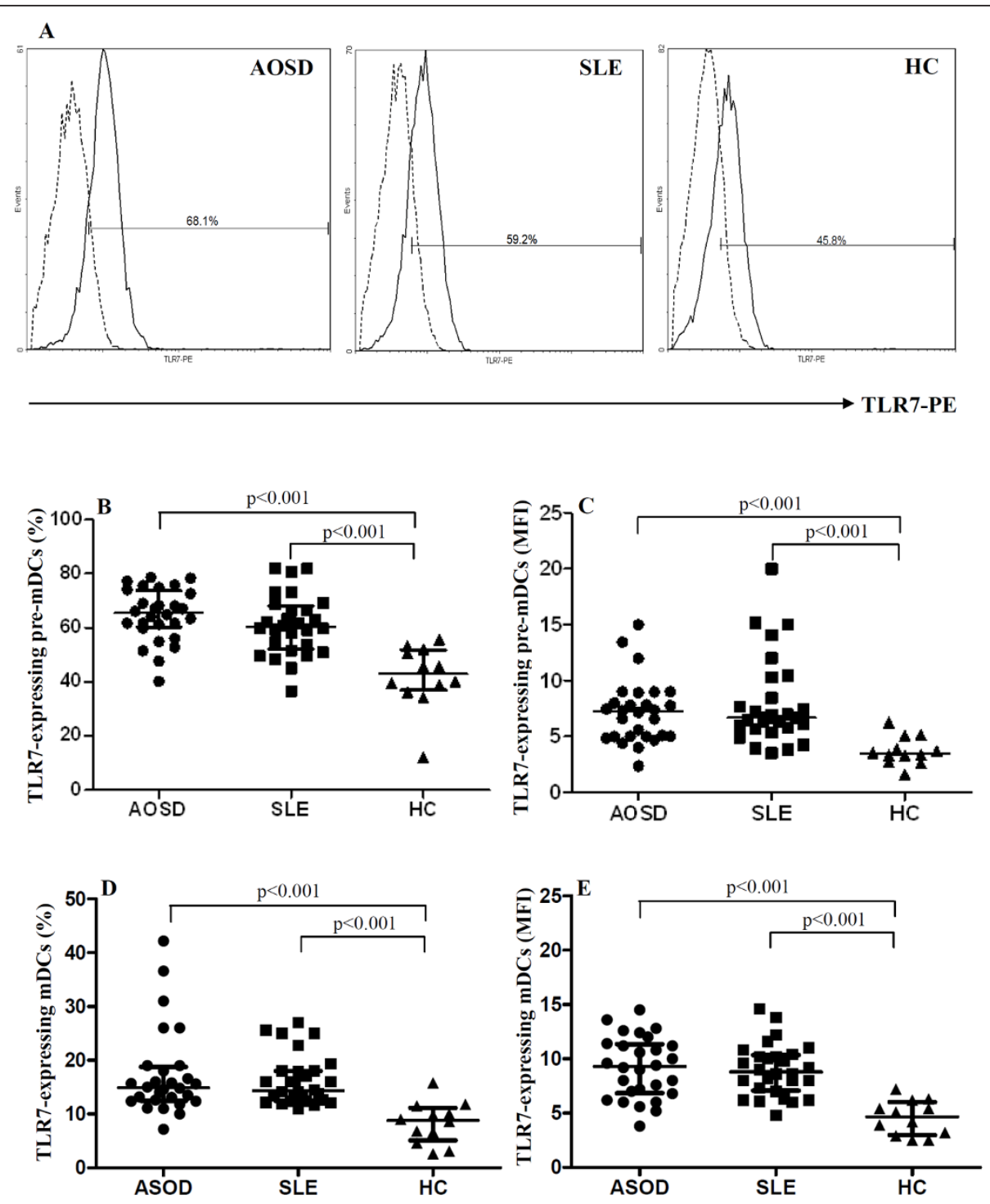

Figure 1 TLR7 expression on circulating precursor myeloid dendritic cells (pre-mDCs) and mDCs in patients with adult-onset Still's disease (AOSD), patients with systemic lupus erythematosus (SLE), and healthy volunteers. Representative examples (A) of flow cytometric histograms of Toll-like receptor (TLR)7 expression in mDcs ( $\mathrm{mDCs}$ ) obtained from peripheral blood of one representative patient with active AOSD, a patient with SLE and a healthy control (HC). The frequencies and mean fluorescence intensity (MFI) of TLR7 expression on circulating pre-mDCs [CD 14 $4^{+} \mathrm{CD} 11 \mathrm{c}^{+}$cells] (B and $\mathbf{C}$, respectively) and mDCs [CD14 CD 11 $\mathrm{c}^{+}$cells] (D and E, respectively) were obtained from 28 patients with active AOSD, 28 with active patients, and $12 \mathrm{HCs}$. The horizontal line indicates the median value for each group. The $P$-value was determined by the Mann-Whitney U-test.

$0.27,1.20 \pm 0.20$; respectively) compared to healthy controls $(1.05 \pm 0.20,1.15 \pm 0.24,0.66 \pm 0.04,1.21 \pm$ $0.07,0.72 \pm 0.14$, respectively). No significant difference was observed between AOSD or SLE patients and healthy controls in the expression levels of IRF-5 protein. Elevated levels of TLR7 expression co-existed with the expression levels of MyD88-dependent signaling molecules. These data suggested an activation of TLR7 signaling pathway in both AOSD patients and SLE patients.
Serum levels of proinflammatory cytokines and IFN- $\alpha$

As shown in Figure 3A-E, significantly higher median levels of serum IL-1 $\beta$, IL-6, IL-18, and IFN- $\alpha$ in patients with active AOSD $(19.65 \mathrm{pg} / \mathrm{mL}$, IQR 3.55 to $32.79 \mathrm{pg} / \mathrm{mL}, 984.98 \mathrm{pg} / \mathrm{mL}$, IQR 409.24 to 2064.92 $\mathrm{pg} / \mathrm{mL}, 2,613.44 \mathrm{pg} / \mathrm{mL}$, IQR 983.04 to $5,765.09 \mathrm{pg} / \mathrm{ml}$, and $45.02 \mathrm{pg} / \mathrm{mL}$, IQR 26.27 to $91.26 \mathrm{pg} / \mathrm{mL}$, respectively) and higher median levels of serum IL-6, IL-18, and IFN- $\alpha$ in active SLE patients $(405.48 \mathrm{pg} / \mathrm{mL}$, IQR 330.32 to $945.83 \mathrm{pg} / \mathrm{mL} ; 605.10 \mathrm{pg} / \mathrm{mL}$, IQR 539.52 to 


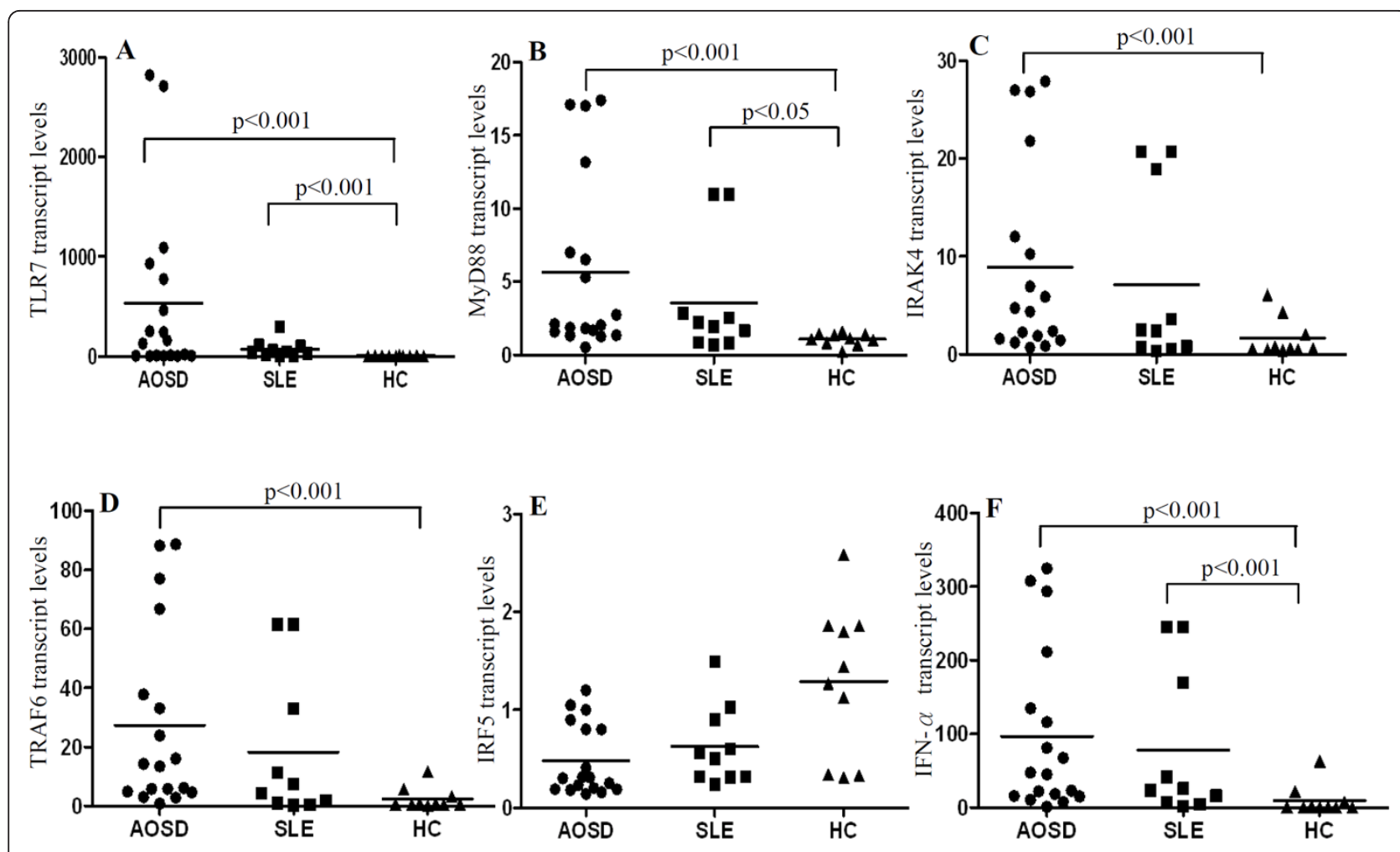

G

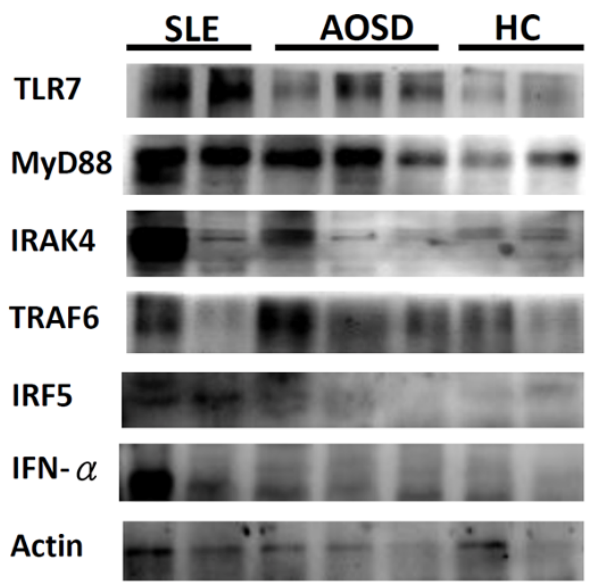

$\mathbf{H}$

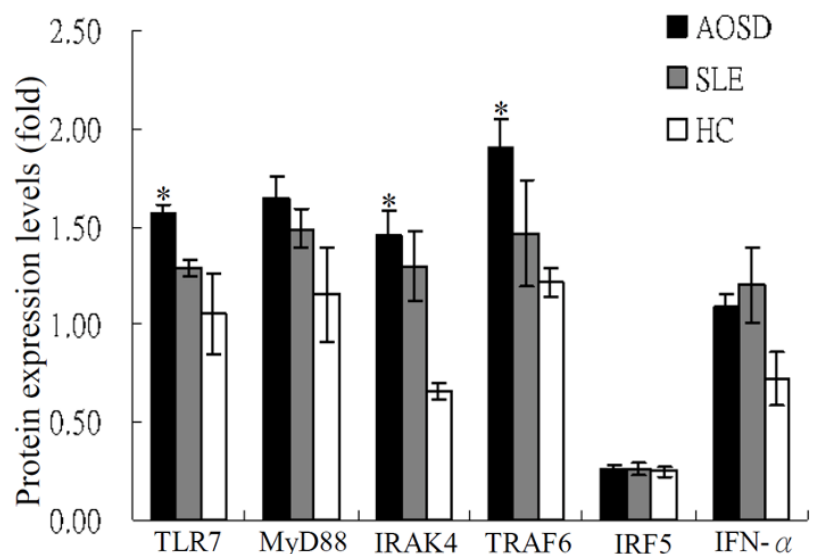

Figure 2 Transcript and protein levels of Toll-like receptor (TLR)7 signaling molecules in patients with adult-onset Still's disease (AOSD), patients with systemic lupus erythematosus (SLE), and healthy volunteers. The comparison in transcript levels of TLR7 signaling molecules, including TLR7 (A), Myeloid differentiation primary-response protein 88 (MyD88) (B), IL-1 receptor-associated kinase (IRAK)4 (C), TNF receptor-associated factor (TRAF)6 (D), IFN regulatory factor (IRF)5 (E), and IFN- $\alpha$ (F) among AOSD patients, SLE patients, and healthy controls $(\mathrm{HCS})$. The horizontal line indicates median value for each group. Immunoblot analyses (G) for protein expression of TLR7 signaling molecules in the lysates of peripheral blood samples from six AOSD patients, three SLE patients and three healthy volunteers. The comparison in the protein expression levels of TLR7 signaling molecules among three groups $(\mathbf{H})$. Bars show the mean \pm standard error of the mean; ${ }^{*} P<0.05$ versus healthy controls (Mann-Whitney U-test). 

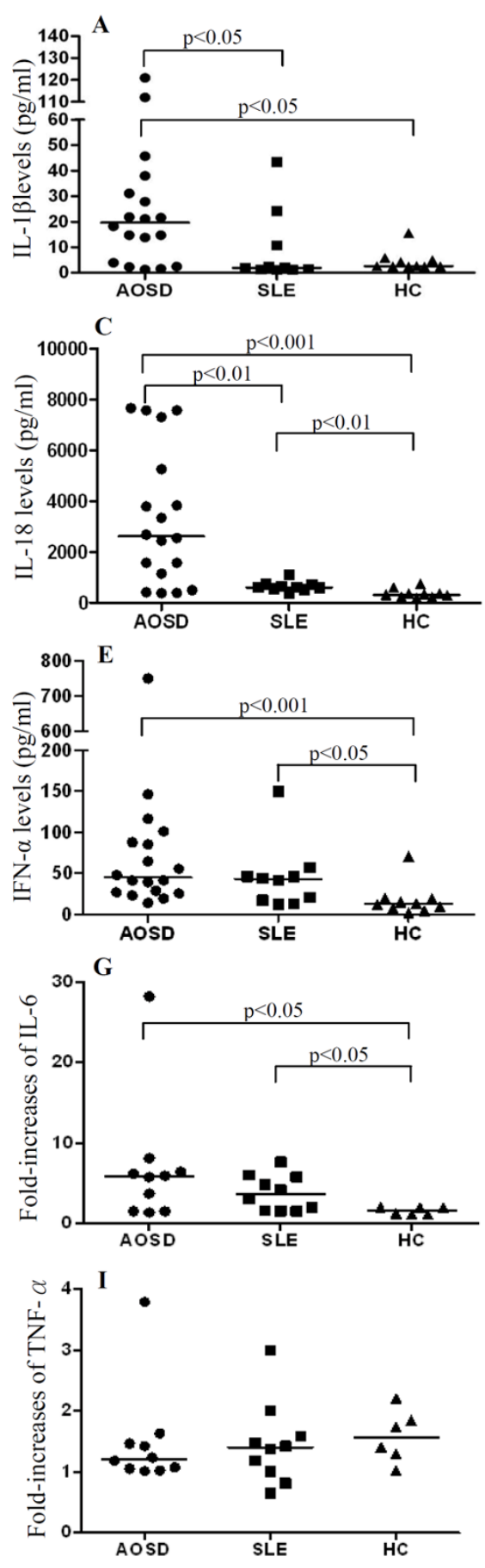

Figure 3 Serum cytokines levels and the fold-increases of supernatant cytokines levels after stimulation with the Toll-like receptor (TLR)7 ligand. The comparison in serum levels of cytokines, including IL-1 $\beta$ (A), IL-6 (B), IL-18 (C), TNF- $\alpha$ (D), and IFN- $\alpha$ (E) among patients with adult-onset Still's disease (AOSD), patients with systemic lupus erythematosus (SLE), and healthy controls (HCs). To explore the functional role of TLR7, we examined the fold-increases of supernatant cytokines levels, including IL-1 $\beta$ (F), IL-6 (G), IL-18 (H), TNF- $\alpha$ (I), and IFN- $\alpha(\mathbf{J})$ after stimulation with the TLR7 ligand (imiquimod $5 \mu \mathrm{g} / \mathrm{mL}$ ) in AOSD patients, SLE patients, and HCs. The horizontal line indicates the median value for each group. The $P$-value was determined by the Mann-Whitney U-test.
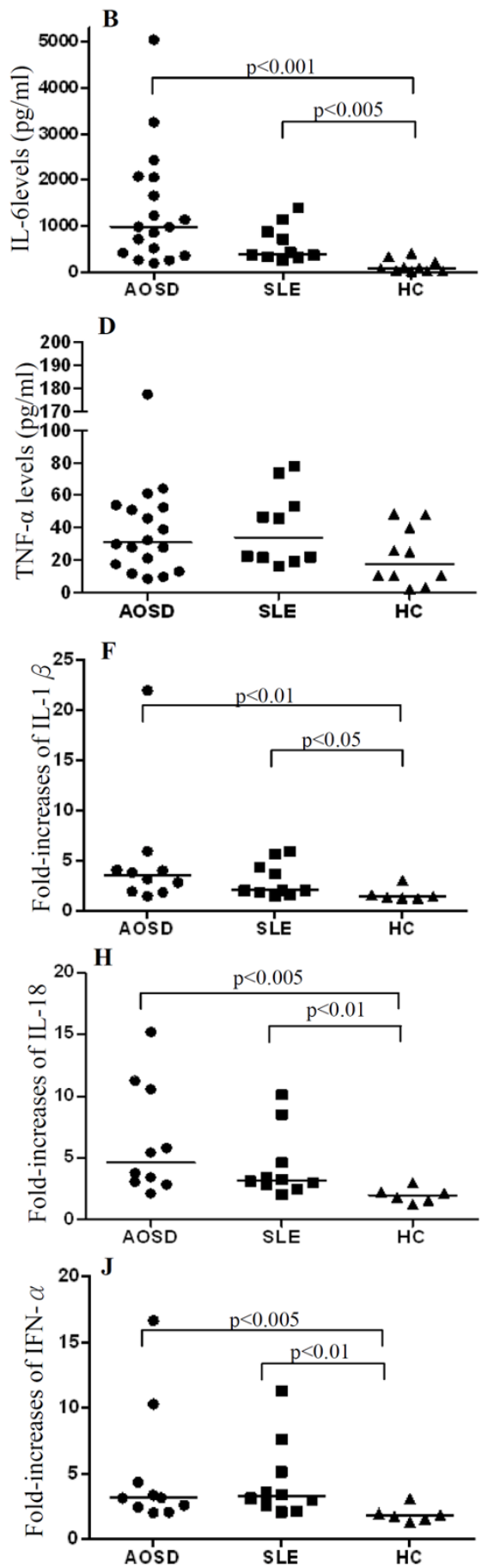
$708.98 \mathrm{pg} / \mathrm{mL}$, and $43.21 \mathrm{pg} / \mathrm{mL}$, IQR 16.23 to $49.12 \mathrm{pg} /$ $\mathrm{mL}$, respectively) were observed when compared to those in healthy controls $(2.61 \mathrm{pg} / \mathrm{mL}$, IQR 2.49 to $5.22 \mathrm{pg} / \mathrm{mL}$, $P<0.05$ for IL-1 $\beta$; $85.78 \mathrm{pg} / \mathrm{mL}$, IQR 33.38 to $249.22 \mathrm{pg} /$ $\mathrm{mL}, P<0.001$ and $P<0.005$ for IL-6; $322.69 \mathrm{pg} / \mathrm{mL}$, IQR 222.50 to $424.03 \mathrm{pg} / \mathrm{mL}, P<0.001$ and $P<0.01$ for IL-18, and $12.79 \mathrm{pg} / \mathrm{mL}$, IQR 6.56 to $19.34 \mathrm{pg} / \mathrm{mL}, P<0.001$ and $P<0.05$ for IFN- $\alpha$ ). However, there were no significant differences between AOSD or SLE patients and healthy controls in serum levels of TNF- $\alpha$.

Correlation between disease activity and circulating levels of TLR7-expressing $\mathrm{mDCs}$ or the transcript levels for TLR7-signaling molecules

The disease activity scores were positively correlated with the percentages of TLR7-expressing pre-mDCs and mDCs in AOSD patients $(r=0.600$ and $r=0.597$, respectively, both $P<0.005)$ and SLE patients $(r=0.477$ and $r=0.422$, respectively, both $P<0.05$ ). As illustrated in Table 2 , the disease activity scores were significantly correlated with transcript levels for TLR7 and MyD88-dependent signaling molecules, including MyD88, TRAF6, and IFN- $\alpha$ in AOSD patients. Similarly, SLEDAI scores were positively correlated with transcript levels of TLR7, MyD88, and
IFN- $\alpha$ in SLE patients. In addition, transcript levels of TLR7 were positively correlated with expression levels of MyD88-dependent signaling molecules, including MyD88, TRAF6, IRAK4, and IFN- $\alpha$ in AOSD patients. The transcript levels of TLR7 and MyD88-dependent signaling molecules were positively correlated with serum levels of IL-1 $\beta$, IL-6, IL-18, and IFN- $\alpha$ in AOSD patients (Table 2).

\section{Functionality of TLR7-mediated production of proinflammatory cytokines and IFN- $\alpha$}

We examined whether this enhanced TLR7 expression was functional in terms of cytokine production. Changes in supernatant levels of TLR7-signaling downstream cytokines on PBMCs treated with TLR7-ligand (imiquimod, $5 \mu \mathrm{g} / \mathrm{mL}$ ) in ten AOSD patients, ten SLE patients and six healthy volunteers were analyzed. Our results showed that TLR7 ligand stimulation of PBMCs from patients with AOSD and SLE induced greater-fold increases of IL-1 $\beta$ (median, 3.5, range 1.5 to $22.0, P<0.01$ and 2.1 , range 1.5 to $6.0, P<0.05$, respectively), IL-6 (median, 5.9, range 1.4 to 28.2 and 3.6 , range 1.5 to 7.6 , respectively, both $P<0.05$ ), IL-18 (median, 4.6, range 3.0 to $10.7, P<0.005$ and 3.2, range 2.7 to $5.6, P<0.01$, respectively), and IFN- $\alpha$ (median, 3.1, range 2.0 to $16.6, P<0.005$ and 3.2 , range 2.1

Table 2 Correlation between transcript levels for TLR7 signaling molecules, and disease activity score and serum cytokine levels in AOSD and SLE patients

\begin{tabular}{|c|c|c|c|c|c|c|}
\hline AOSD patients & TLR7 & MyD88 & TRAF6 & IRAK4 & IRF5 & IFN- $\alpha$ \\
\hline Activity score & $0.766^{* * *}$ & $0.493^{*}$ & $0.481^{*}$ & $0.488^{*}$ & 0.151 & $0.489^{*}$ \\
\hline MyD88 transcript & $0.818^{* * *}$ & - & & & & \\
\hline TRAF6 transcript & $0.742^{* * *}$ & $0.789^{* * *}$ & - & & & \\
\hline IRAK4 transcript & $0.701^{* *}$ & $0.746^{* * *}$ & $0.986^{* * *}$ & - & & \\
\hline IRF5 transcript & 0.241 & 0.223 & 0.231 & 0.218 & - & \\
\hline IFN- $\alpha$ transcript & $0.713^{* *}$ & $0.738^{* * *}$ & $0.988^{* * *}$ & $0.986^{* * *}$ & 0.254 & - \\
\hline Serum IL-1 $\beta$ level & $0.626^{* *}$ & 0.424 & $0.589^{*}$ & $0.531^{*}$ & -0.131 & $0.556^{*}$ \\
\hline Serum IL-6 level & $0.589^{*}$ & $0.571^{*}$ & $0.476^{*}$ & 0.434 & -0.131 & 0.455 \\
\hline Serum IL-18 level & $0.732^{* *}$ & $0.531^{*}$ & 0.451 & 0.459 & -0.033 & 0.408 \\
\hline Serum TNF- $\alpha$ level & 0.117 & 0.030 & 0.104 & 0.059 & -0.094 & 0.036 \\
\hline Serum IFN- $\alpha$ level & $0.482^{*}$ & $0.517^{*}$ & $0.558^{*}$ & $0.589^{*}$ & -0.429 & $0.571^{*}$ \\
\hline SLE patients & TLR7 & MyD88 & TRAF6 & IRAK4 & IRF5 & IFN- $\alpha$ \\
\hline SLEDAI score & $0.782^{* *}$ & $0.731^{*}$ & 0.486 & 0.517 & 0.355 & $0.698^{*}$ \\
\hline MyD88 transcript & $0.806^{* *}$ & - & & & & \\
\hline TRAF6 transcript & 0.564 & $0.842^{* * *}$ & - & & & \\
\hline IRAK4 transcript & 0.515 & $0.685^{*}$ & $0.939^{* * *}$ & - & & \\
\hline IRF5 transcript & 0.115 & -0.236 & -0.152 & 0.127 & - & \\
\hline IFN- $\alpha$ transcript & $0.661^{*}$ & $0.855^{* * *}$ & $0.976^{* * *}$ & $0.952^{* * *}$ & -0.139 & - \\
\hline Serum IL-1 $\beta$ level & $0.661^{*}$ & 0.334 & 0.298 & 0.225 & -0.103 & 0.274 \\
\hline Serum IL-6 level & 0.624 & 0.134 & 0.036 & 0.012 & -0.024 & 0.036 \\
\hline Serum IL-18 level & $0.770^{* *}$ & $0.770^{* *}$ & $0.648^{*}$ & 0.588 & -0.055 & $0.721^{*}$ \\
\hline Serum TNF- $\alpha$ level & 0.261 & 0.219 & 0.413 & 0.547 & -0.292 & 0.474 \\
\hline Serum IFN- $\alpha$ level & 0.212 & 0.456 & 0.359 & 0.444 & -0.395 & 0.298 \\
\hline
\end{tabular}

AOSD, adult-onset Still's disease; SLE, systemic lupus erythematosus; SLEDAI, SLE disease activity index; MyD88, Myeloid differentiation primary-response protein 88; TRAF6, TNF receptor associated factor-6; IRAK4, IL-1 receptor-associated kinase-4; IRF5, interferon regulatory factor-5. ${ }^{*} P<0.05,{ }^{* *} P<0.01,{ }^{* * *} P<0.001$ (Spearman's rank correlation test). 


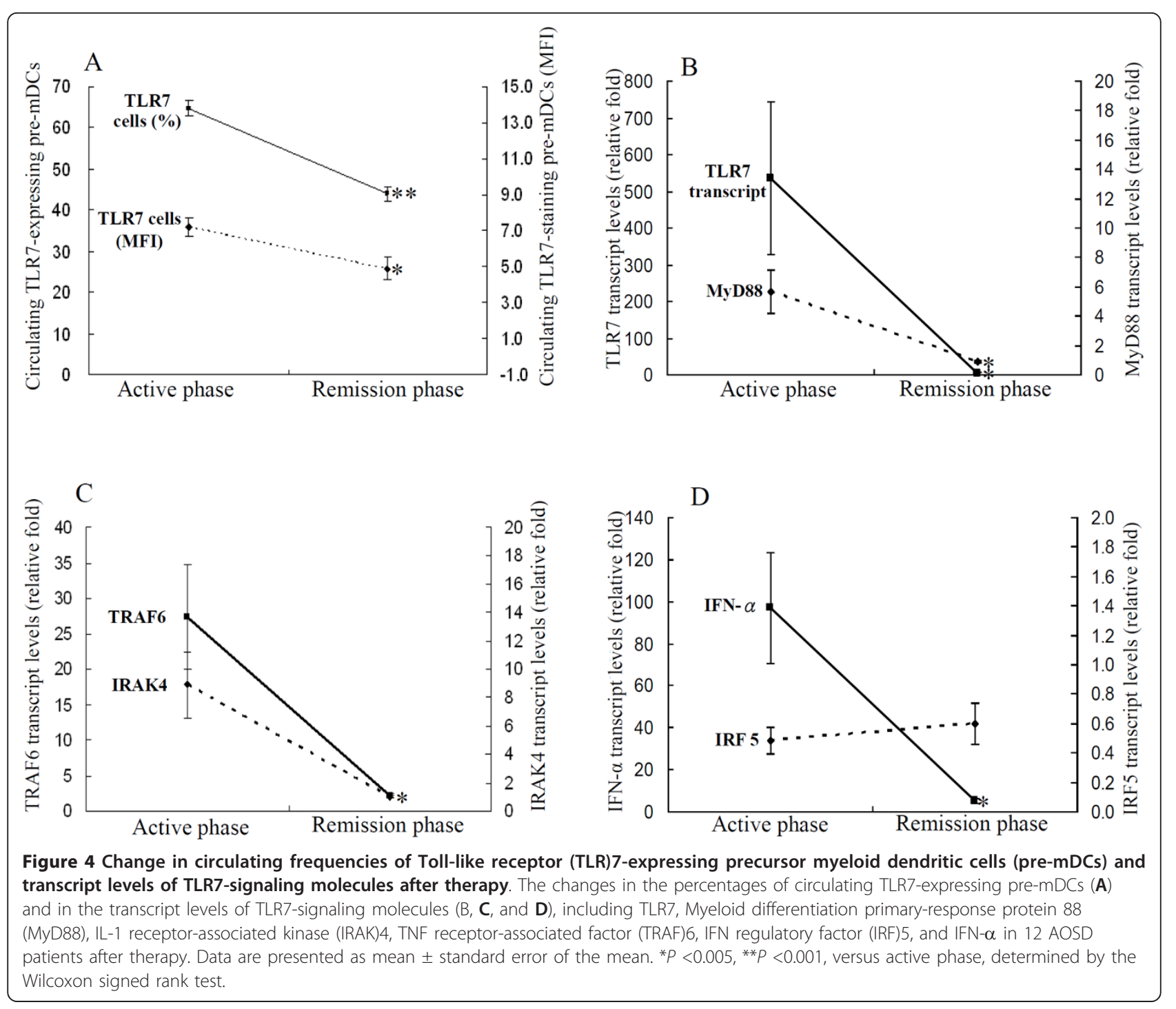

to $11.3, P<0.01$, respectively) compared with PBMCs from healthy controls (median, 1.4 , range 1.3 to $3.1 ; 1.6$, range 1.1 to 2.0 ; 2.0 , range 1.5 to 2.4 ; and 1.8 , range 1.3 to 3.1 , respectively, Figure 3F-H). However, imiquimod stimulation of PBMCs did not result in significant amplification of TNF- $\alpha$ in AOSD patients or SLE patients.

\section{Changes in expression levels of TLR7 MyD88-dependent signaling molecules in AOSD patients after therapy}

Eighteen AOSD patients were available for examination of TLR7-signaling expression in both the active phase and the remission phase. As shown in Figure 4A, the percentages and MFI of TLR7-expressing pre-mDCs significantly decreased (mean \pm SEM, $64.78 \pm 1.83$ vs. $43.95 \pm 1.82$; $7.19 \pm 0.54$ vs. $4.90 \pm 0.61$, respectively, both $P<0.001$ ), paralleling clinical remission and the decrease in serum ferritin levels $(931.5 \pm 201.3 \mu \mathrm{g} / \mathrm{L}$ vs. $234.4 \pm 28.3 \mu \mathrm{g} / \mathrm{L}$, $P<0.001)$ in AOSD patients. Similarly, the transcript levels for TLR7-signaling molecules including TLR7, MyD88, TRAF6, IRAK4, and IFN- $\alpha$ significantly decreased (535.8 \pm 207.8 vs. $2.93 \pm 2.26, P<0.001 ; 5.66 \pm 1.44$ vs. $0.92 \pm$ $0.09, P<0.001 ; 27.40 \pm 7.33$ vs. $2.10 \pm 0.35, P<0.005 ; 8.90$ \pm 2.34 vs. $1.02 \pm 0.12, P<0.005 ; 96.94 \pm 26.29$ vs. $4.99 \pm$ $1.07, P<0.001$, respectively, Figure $4 \mathrm{~B}, \mathrm{C}$, and $\mathrm{D})$, paralleling the decrease in disease activity score $(6.44 \pm 0.40$ vs. $3.78 \pm 0.15, P<0.001)$ in AOSD patients.

\section{Discussion}

This study is the first attempt to characterize the expression of TLR7 on mDCs and TLR7 MyD88-dependent signaling molecules on PBMCs in AOSD patients. In order to avoid the effects of immunosuppressive agents on our results, new-onset untreated AOSD patients were enrolled. Our results showed significantly elevated frequencies of TLR7-expressing $\mathrm{mDCs}$ and upregulated levels of TLR7 transcript and protein on PBMCs. The 
expression levels of TLR7 were positively correlated with disease activity in AOSD patients. Moreover, a parallel decrease in TLR7 expression levels with disease remission was found in our AOSD patients. Our observations indicate that TLR7 overexpression is involved in the pathogenesis of AOSD. However, a large prospective study should be conducted to confirm our findings.

Similar to AOSD patients, our SLE patients had significantly elevated frequencies of circulating TLR7-expressing mDCs and upregulated levels of TLR7 expression, which were correlated with SLEDAI scores. Our results were consistent with the findings of recent studies showing elevated expression levels of circulating TLR7 transcript using the qPCR method [25], and were similar to the results of recent studies showing a role for TLR7 genes in the predisposition of Asian populations to SLE [33,34]. In addition, Christensen et al. revealed that TLR7-deficient lupus-prone mice had ameliorated disease and decreased lymphocyte activation [35]. These findings suggest that TLR7 expression is involved in the pathogenesis of SLE, and elevated frequencies of TLR7-expressing pre-mDCs and $\mathrm{mDCs}$ may be a common characteristic of systemic inflammatory diseases including AOSD and SLE.

TLR7 ligation triggers activation of a group of cytosolic adaptor molecules [11]. MyD88 acts as an adaptor that recruits the serine-threonine kinase IRAK and TRAF6 to the TLR7 signaling pathway. MyD88-mediated signaling lies at the center of the TLR-driven immune response $[2,11,36]$, and leads to production of proinflammatory cytokines and type I IFN $[10,11,37]$. Our results showed elevated transcript and protein levels of TLR7 MyD88dependent signaling molecules, including MyD88, IRAK4 and TRAF6 on PBMCs from both AOSD patients and SLE patients. Moreover, a positive correlation between disease activity and the expression levels of TLR7 MyD88-dependent signaling molecules were observed in both AOSD patients and SLE patients (Table 2). In concordance with the findings of previous studies showing that TLR7 activation triggers production of proinflammatory cytokines $[10,11,38]$, our results showed elevated levels of serum IL$1 \beta$, IL- 6 , IL- 18 , and IFN- $\alpha$ positively correlated with the expression levels of TLR7 signaling molecules in AOSD patients. These observations suggest the pathogenic role of the TLR7 MyD88-dependent signaling pathway in AOSD. Although IRF5 is important for regulation of IFN- $\alpha$ after TLR activation [39], the absence of a significant increase in IRF5 expression in our patients may be related to the enrolled patients' characteristics, differences in experimental procedures and/or the small sample size in our study.

Accumulating evidence shows that IFN- $\alpha$, a type I IFN, plays a pivotal role in triggering and sustaining inflammatory diseases $[40,41]$. Previous studies have identified type I IFN gene expression in PBMCs from patients with active lupus [42,43], and overproduction of
IFN- $\alpha$, which correlates with disease exacerbation in SLE $[43,44]$. Although there are no data on IFN- $\alpha$ in AOSD, elevated levels of IFN- $\alpha$, which correlated with disease activity in our AOSD patients, suggest the potential role of IFN- $\alpha$ in AOSD pathogenesis. Moreover, we observed a positive correlation between expression levels of TLR7-signaling molecules and IFN- $\alpha$ level in AOSD patients and SLE patients, consistent with the findings of a previous study showing the concordant overexpression of TLR7 and IFN- $\alpha$ in SLE patients [25] and IFN- $\alpha$ production requiring TLR7/MyD88 signaling in experimental mouse lupus [45]. Our results support the observation that TLR7 inhibitors have a therapeutic application in autoimmune dermatitis with a prominent IFN- $\alpha$ signature [46].

Given a positive association of TLR7 expression with levels of proinflammatory cytokines, we further investigated the functional relation between TLR7 ligation and the downstream mediators. Our results showed that TLR7 ligand (imiquimod) stimulation of PBMCs induced greater-fold increases in IL- $1 \beta$ levels (up to around 22 -fold), IL-6 (up to around 28-fold), IL-18 (up to around15-fold), and IFN- $\alpha$ (up to around 17-fold) in AOSD patients compared to those in healthy controls, indicating that the upregulation of TLR7 is functional. Moreover, we revealed that the cytokine pattern induced by TLR7 ligand stimulation overlaps with a similar serum cytokine panel observed in both AOSD and SLE (Figure 3 ), suggesting that TLR7 triggering has an important contribution to the inflammatory response in both diseases. Our results were consistent with the findings of a study showing that imiquimod induced production of proinflammatory cytokines and IFN- $\alpha$ [32]. Our data also showed enhanced production of IL-18 after TLR7 ligand stimulation, supporting the findings of sharing of the TLR7 with IL-18 receptor signaling [2,47]. However, our results are different from the findings of a recent study showing no significant difference in the induction of all measured cytokines between SLE patients and controls [24]. This discrepancy may be related to the difference in the TLR7 ligand used (R837 vs. imiquimod in our study) and in disease activity in SLE patients in our study (SLEDAI, mean \pm SD, $3.1 \pm 3.0$ vs. $7.8 \pm 2.3$ ).

Our longitudinal follow-up of AOSD patients showed that the expression levels of TLR7 MyD88-dependent signaling molecules, including TLR7, MyD88, IRAK4, TRAF6, and IFN- $\alpha$, decreased significantly, paralleling the clinical remission and a decrease in inflammatory parameters after therapy (Figure 4). Our results support the hypothesis that inhibitors of TLR7 signaling and anti-IFN- $\alpha$ therapy, can be a promising therapeutic modality for systemic inflammatory diseases [9,48-51].

There were some limitations in our study. Because it was difficult to obtain biopsy tissue, we could not 
investigate the expression of TLR7 signaling molecules on lesion specimens in AOSD patients. To prove that TLR7 signaling is active in AOSD in vivo, further study to investigate phosphorylation of signaling molecules in freshly isolated cells is needed. The lack of significant correlations between expression levels of TLR7 signaling and clinical features of AOSD may be due to the small sample size in this clinically heterogeneous disease. In addition, it is likely that more than one TLR pathway is needed for the initiation of inflammatory response in AOSD. Therefore, a previous investigation suggested that simultaneous or sequential triggering of different TLR pathways is needed to develop an inflammatory disease [52].

\section{Conclusions}

Our results show that TLR7 activation with increased production of proinflammatory cytokines and IFN- $\alpha$ through MyD88-dependent signaling may be involved in the pathogenesis of both AOSD and SLE. We also provide the first evidence that IFN- $\alpha$ overexpression may have a possible link with immune response in AOSD. Such studies are of translational and fundamental interest, because they can provide potentially therapeutic modalities [48-51], and may shed light on the etiopathogenesis of the TLR7 signaling pathway in systemic inflammatory diseases. Further study on the pathobiology of the TLR7 MyD88-dependent signaling pathway in AOSD is needed.

\begin{abstract}
Abbreviations
ACR: American College of Rheumatology: AOSD: adult-onset Still's disease; BSA: bovine serum albumin; Ct: threshold cycle; DMARD: disease-modifying anti-rheumatic drug; ELISA: enzyme-linked immunosorbent assay; FITC: fluorescein isothiocyanate; GAPDH: glyceraldehyde-3-phosphate dehydrogenase; IFN-a: interferon-a; IL: interleukin; IRAK: IL-1 receptorassociated kinase; IRF: IFN regulatory factor; mAb monoclonal antibody; mDC: myeloid dendritic cell; MFI: mean fluorescence intensity; MyD88: myeloid differentiation primary-response protein 88; NSAID: non-steroidal anti-inflammatory drug; PBMC: peripheral blood mononuclear cell; PCR: polymerase chain reaction; PE-Cy5: phycoerythrin-Cyanin 5; GPCR: quantitative PCR; PVDF: polyvinylidene difluoride membrane; RPMI: Roswell Park Memorial Institute; SLE: systemic lupus erythematosus; SLEDAI: SLE disease activity index; TBST: Tris-buffered saline and Tween 20; TLR: Toll-like receptor; TNF: tumor necrosis factor; TRAF: TNF receptor-associated factor.
\end{abstract}

\section{Authors' contributions}

All authors made substantive intellectual contributions to the present study and approved the final manuscript. DYC conceived the study, generated the original hypothesis, designed the study, acquired clinical data, analyzed data, and drafted and revised the manuscript. CCL generated the original hypothesis, designed the study, analyzed data and drafted the manuscript. YMC, WTH, and JLL acquired clinical data and performed statistical analysis. HHC, KLL, and CWH performed clinical assessments on study subjects.

\section{Competing interests}

The authors declare that they have no competing interests.

\section{Acknowledgements}

This work was supported by a grant from the National Science Council, Taiwan (NSC-98-2314-B-075A-003-MY3).

\section{Author details}

${ }^{1}$ Faculty of Medicine, National Yang-Ming University, No. 155, Sec. 2, Li-Nong Street, Taipei 112, Taiwan. ${ }^{2}$ Division of Allergy, Immunology and Rheumatology, Taichung Veterans General Hospital, No. 160, Section 3, Taichung-Kang Road, Taichung, 407, Taiwan. Infection and Immunity Research Center, National Yang-Ming University, No. 155, Sec. 2, Li-Nong Street, Taipei 112, Taiwan. ${ }^{4}$ Institute of Microbiology and Immunology, Chung-Shan Medical University, No.110, Sec.1, Jianguo N.Rd., Taichung, 402, Taiwan. ${ }^{5}$ Institute of Biomedical Science, National Chung-Hsing University, No.250, Kuo-Kuang Rd., Taichung, 402, Taiwan. " Division of Immunology and Rheumatology, China Medical University Hospital, No. 2, Yu-De Rd., Taichung, 404, Taiwan

Received: 5 August 2012 Revised: 29 January 2013

Accepted: 26 February 2013 Published: 4 March 2013

\section{References}

1. Hemmi H, Takeuchi O, Kawai T, Kaisho T, Sato S, Sanjo H, Matsumoto M, Hoshino K, Wagner H, Takeda K, Akira S: A Toll-like receptor recognizes bacterial DNA. Nature 2000, 408:740-745.

2. Akira S, Uematsu S, Takeuchi O: Pathogen recognition and innate immunity. Cell 2006, 124:783-801.

3. Marshak-Rothstein A: Toll-like receptors in systemic autoimmune disease. Nat Rev Immunol 2006, 6:823-835.

4. Christensen SR, Shlomchik MJ: Regulation of lupus-related autoantibody production and clinical disease by Toll-like receptors. Semin Immunol 2007, 19:11-23.

5. Hemmi H, Kaisho T, Takeuchi O, Sato S, Sanjo H, Hoshino K, Horiuchi T, Tomizawa H, Takeda K, Akira S: Small anti-viral compounds activate immune cells via the TLR7 MyD88-dependent signaling pathway. Nat Immunol 2002, 3:196-200

6. Ito T, Amakawa R, Kaisho T, Hemmi H, Tajima K, Uehira K, Ozaki Y, Tomizawa H, Akira S, Fukuhara S: Interferon-alpha and interleukin-12 are induced differentially by Toll-like receptor 7 ligands in human blood dendritic cell subset. J Exp Med 2002, 195:1507-1512.

7. Thibault DL, Graham KL, Lee LY, Balboni I, Hertzog PJ, Utz PJ: Type 1 interferon receptor controls B-cell expression of nucleic acid-sensing Toll-like receptors and autoantibody production in a murine model of lupus. Arthritis Res Ther 2009, 11:R112.

8. Arthur M, Krieg Jörg Vollmer: Toll-like receptor 7, 8 and 9: linking innate immunity to autoimmunity. Immunological Reviews 2007, 220:251-269.

9. Barrat FJ, Meeker T, Gregorio J, Chan JH, Uematsu S, Akira S, Chang B, Duramad O, Coffman RL: Nucleic acids of mammalian origin can act as endogenous ligands for Toll-like receptors and may promote systemic lupus erythematosus. J Exp Med 2005, 202:1131-1139.

10. Pawar RD, Ramanjaneyulu A, Kulkarni OP, Lech M, Segerer S, Anders HJ: Inhibition of Toll-like receptor-7 (TLR-7) or TLR-7 plus TLR-9 attenuates glomerulonephritis and lung injury in experimental lupus. J Am Soc Nephrol 2007, 18:1721-1731.

11. Akira S, Takeda K: Toll-like receptor signaling. Nat Rev Immunol 2004, 4:499-511.

12. Sun D, Ding A: MyD88-mediated stabilization of interferon-gammainduced cytokine and chemokine mRNA. Nat Immunol 2006, 7:375-381.

13. Bywaters EGL: Still's disease in the adults. Ann Rheum Dis 1971, 30:121-133.

14. Ohta A, Yamaguchi M, Kaneoka H, Nagayoshi T, Hiida M: Adult Still's disease: Review of 228 cases from the literature. J Rheumatol 1987, 14:1139-1146.

15. Wouters JMGW, van der Veen J, van de Putte LBA, de Rooij DJRAM: Adult Still's disease and viral infection. Ann Rheum Dis 1988, 47:764-767.

16. Chen DY, Chen YM, Lan JL, Tzang BS, Lin CC, Hsu TC: Significant association of past parvovirus B19 infection with cytopenia in both adult-onset Still's disease and systemic lupus erythematosus patients. Clin Chim Acta 2012, 413:855-860

17. Fujii T, Nojima T, Yasuoka H, Satoh S, Nakamura K, Kuwana M, Suwa A, Hirakata M, Mimori T: Cytokine and immunogenetic profiles in Japanese patients with adult Still's disease: association with chronic articular disease. Rheumatology 2001, 40:1398-1404.

18. Choi JH, Suh CH, Lee YM, Suh YJ, Lee SK, Kim SS, Nahm DH, Park HS: Serum cytokine profiles in patients with adult onset Still's disease. J Rheumatol 2003, 30:2422-2427. 
19. Chen DY, Hsieh TY, Hsieh CW, Lin FJ, Lan JL: Increased apoptosis of peripheral blood lymphocytes and its association with interleukin-18 in patients with active untreated adult-onset Still's disease. Arthritis Rheum 2007, 57:1530-1538.

20. Savarese E, Chae OW, Trowitzsch S, Weber G, Kastner B, Akira S, Wagner H, Schmid RM, Bauer S, Krug A: U1 small nuclear ribonucleoprotein immune complexes induce type I interferon in plasmacytoid dendritic cells through TLR7. Blood 2006, 107:3229-3234.

21. Yu CF, Peng WM, Oldenburg J, Hoch J, Bieber T, Limmer A, Hartmann G, Barchet W, Eis-Hübinger AM, Novak N: Human plasmacytoid dendritic cells support Th17 cell effector function in response to TLR7 ligation. J Immunol 2010, 184:1159-1167.

22. Lombardi V, Van Overtvelt L, Horiot S, Moingeon P: Human dendritic cells stimulated via TLR7 and/or TLR8 induce the sequential production of II10, IFN-gamma, and IL-17A by naive CD4+ T cells. J Immunol 2009, 182:3372-3379.

23. Chen DY, Chen YM, Lan JL, Lin CC, Chen HH, Hsieh CW: Potential role of Th17 cells in the pathogenesis of adult-onset Still's disease. Rheumatology (Oxford) 2010, 49:2305-2312.

24. Wong CK, Wong PTY, Tam LS, Li EK, Chen DP, and Lam CWK: Activation profile of Toll-like receptors of peripheral blood lymphocytes in patients with systemic lupus erythematosus. Clin Exp Immunol 2009, 159:11-22.

25. Komatsuda A, Wakui H, Iwamoto K, Ozawa M, Togashi M, Masai R, Maki N Hatakeyama T, Sawada K: Up-regulated expression of Toll-like receptors mRNAs in peripheral blood mononuclear cells from patients with systemic lupus erythematosus. Clin Exp Immunol 2008, 152:482-487.

26. Yamaguchi M, Ohta A, Tsunematsu T, Kasukawa R, Mizushima Y, Kashiwagi H, Kashiwazaki S, Tanimoto K, Matsumoto Y, Ota T: Preliminary criteria for classification of adult Still's disease. J Rheumatol 1992, 19:424-430.

27. Rau M, Schiller M, Krienke S, Heyder P, Lorenz H, Blank N: Clinical manifestations but not cytokine profiles differentiate adult-onset Still's disease and sepsis. J Rheumatol 2010, 37:2369-2376.

28. Hochberg MC: Updating the American College of Rheumatology revised criteria for the classification of systemic lupus erythematosus. Arthritis Rheum 1997, 40:1725.

29. Bombaridier C, Gladman DD, Urowitz MB, Caron D, Chang CH: Derivation of the SLEDAl: a disease activity index for lupus patients. The Committee on Prognosis Studies in SLE. Arthritis Rheum 1992, 35:630-640.

30. Chomczynski P, Sacchi N: Single-step method of RNA isolation by acid guanidium thiocyanate-phenol-chloroform extraction. Anal Biochem 1987, 162:156-159.

31. Chuang HC, Lan JL, Chen DY, Yang CY, Chen YM, Li JP, Huang CY, Liu PE, Wang X, Tan TH: GLK controls autoimmunity and NF-kB signaling by activating PKC $\theta$ in T cells. Nature Immunol 2011, 12:1113-1118.

32. Testerman TL, Gerster JF, Imbertson LM, Reiter MJ, Miller RL, Gibson SJ, Wagner TL, Tomai MA: Cytokine induction by the immunomodulators imiquimod and S-27609. J Leukoc Biol 1995, 58:365-372.

33. Shen N, Fu Q, Deng Y, Qian X, Zhao J, Kaufman KM, Wu YL, Yu CY, Tang Y, Chen JY, Yang W, Wong M, Kawasaki A, Tsuchiya N, Sumida T, Kawaguchi Y, Howe HS, Mok MY, Bang SY, Liu FL, Chang DM, Takasaki Y, Hashimoto H, Harley JB, Guthridge JM, Grossman JM, Cantor RM, Song YW, Bae SC, Chen S, Hahn BH, Lau YL, Tsao BP: Sex-specific association of X-linked Toll-like receptor 7 (TLR7) with male systemic lupus erythematosus. Proc Natl Acad Sci USA 2010, 107:15838-15843.

34. Kawasaki A, Furukawa H, Kondo Y, Ito S, Hayashi T, Kusaoi M, Matsumoto I, Tohma S, Takasaki Y, Hashimoto H, Sumida T, Tsuchiya N: TLR7 single nucleotide polymorphisms in the $3^{\prime}$ untranslated region and intron independently contribute to systemic lupus erythematosus in Japanese woman: a case-control association study. Arthritis Res Ther 2011, 13:R41.

35. Christensen SR, Shupe J, Nickerson K, Kashgarian M, Flavell RA, Shlomchik MJ: Toll-like receptor 7 and TLR9 dictate autoantibody specificity and have opposing inflammatory and regulatory roles in a murine model of lupus. Immunity 2006, 25:417-428.

36. Kissner TL, Ruthel G, Cisney ED, Ulrich RG, Fernandez S, Saikh KU: MyD88dependent proinflammatory cytokine response contributes to lethal toxicity of staphylococcal enterotoxin B in mice. Innate Immun 2010, 17:451-462.

37. Akira S, Takoda K, Kaisho I: Toll-like receptors: critical proteins linking innate and acquired immunity. Nature Immunol 2001, 2:675-680.
38. Matsushima H, Yamada N, Matsue H, Shimada S: TLR3-, TLR7-, and TLR9mediated production of proinflammatory cytokines and chemokines from murine connective tissue type skin-derived mast cells but not from bone marrow-derived mast cells. J Immunol 2004, 173:531-541.

39. Niewold TB, Kelly JA, Flesch MH, Espinoza LR, Harley JB, Crow MK: Association of the IRF5 risk haplotype with high serum interferon-alpha activity in systemic lupus erythematosus. Arthritis Rheum 2008, 58:2481-2487.

40. Theofilopoulos AN, Baccala R, Beutler B, Kono DH: Type I interferons (alpha/beta) in immunity and autoimmunity. Annu Rev Immunol 2005, 23:307-336.

41. Ronnblom L, Alm VG: Systemic lupus erythematosus and type 1 interferon system. Arthritis Res Ther 2003, 5:68-75.

42. Baechler EC, Batliwalla FM, Karypis G, Gaffney PM, Ortmann WA, Espe KJ, Shark KB, Grande WJ, Hughes KM, Kapur V, Gregersen PK, Behrens TW: Interferon-inducible gene expression signature in peripheral blood cells of patients with severe lupus. Proc Natl Acad Sci USA 2003, 100:2610-2615.

43. Feng $X$, Wu H, Grossman JM, FitzGerald JD, Park GS, Dong X, Chen W, Kim MH, Weng HH, Furst DE, Gorn A, McMahon M, Taylor M, Brahn E, Hahn BH, Tsao BP: Association of increased interferon-inducible gene expression with disease activity and lupus nephritis in patients with systemic lupus erythematosus. Arthritis Rheum 2006, 54:2951-2962.

44. Dalléra MC, Cardarelli PM, Preston BT, Witte A, Davis JC Jr: Type I interferon correlates with serological and clinical manifestations of SLE. Ann Rheum Dis 2005, 64:1692-1697.

45. Lee PY, Kumagai Y, Li Y, Takeuchi O, Yoshida H, Weinstein J, Kellner ES, Nacionales D, Barker T, Kelly-Scumpia K, van Rooijen N, Kumar H, Kawai T, Satoh M, Akira S, Reeves WH: TLR7-dependent and FcyR-independent production of type I interferon in experimental mouse lupus. J Exp Med 2008, 205:2995-3006.

46. Guiducci C, Tripodo C, Gonng M, Sangaletti S, Colombo MP, Coffman RL, Barrat FJ: Autoimmune skin inflammation is dependent on plasmacytoid dendritic cell activation by nucleic acids via TLR7 and TLR9. J Exp Med 2010, 207:2931-2942.

47. Adachi O, Kawai T, Takeda K, Matsumoto M, Tsutsui H, Sakagami M, Nakanishi K, Akira S: Targeted disruption of the MyD88 gene results in loss of IL-1- and IL-18-mediated function. Immunity 1998, 9:143-150.

48. Lenert PS: Targeting Toll-like receptor signaling in plasmacytoid dendritic cells and autoreactive B cells as a therapy for lupus. Arthritis Res Ther 2006, 8:203.

49. Barrat FJ, Meeker T, Chan JH, Guiducci C, Coffman RL: Treatment of lupusprone mice with a dual inhibitor of TLR7 and TLR9 leads to reduction of autoantibody production and amelioration of disease symptoms. Eur $J$ Immunol 2007, 37:3582-3586.

50. Yao Y, Richman L, Higgs BW, Morehouse CA, de los Reyes M, Brohawn P, Zhang J, White B, Coyle AJ, Kiener PA, Jallal B: Neutralization of interferonalpha/beta-inducible genes and downstream effect in a phase I trial of an anti-interferon-alpha monoclonal antibody in systemic lupus erythematosus. Arthritis Rheum 2009, 60:1785-1796.

51. Merrill JT, Wallace DJ, Petri M, Kirou KA, Yao Y, White WI, Robbie G, Levin R, Berney SM, Chindalore V, Olsen N, Richman L, Le C, Jallal B, White B: Lupus Interferon Skin Activity (LISA) Study Investigators.Safety profile and clinical activity of sifalimumab, a fully human anti-interferon a monoclonal antibody, in systemic lupus erythematosus: a phase I, multicentre, double-blind randomised study. Ann Rheum Dis 2011, 70:1905-1913.

52. Hamilton-Williams EE, Lang A, Benke D, Davey GM, Wiesmuller KH, Kurts C: Cutting edge: TLR ligands are not sufficient to break cross-tolerance to self-antigens. J Immunol 2005, 174:1159-1163.

\section{doi:10.1186/ar4193}

Cite this article as: Chen et al:: Involvement of TLR7 MyD88-dependent signaling pathway in the pathogenesis of adult-onset Still's disease. Arthritis Research \& Therapy 2013 15:R39. 